\section{External Ophthalmomyiasis Report in Jordan Valley}

\author{
Omran H. Alameri \\ Department of Basic Medical Sciences, \\ Jordan University of Science and \\ Technology, Irbid, Jordan
}

\begin{abstract}
A young farmer from Northern Jordan Valley in close contact with sheep was infected accidentally in early May 2014 with the larvae of oestrus ovis. The deposition of larvae in his eye lead to inflammation accompanied with severe pain and irritation. The inflammatory signs disappeared five days after receiving the medical care. The infection is more prevalent in almost all ages of males. External ophthalmomyiasis should be considered in susceptible individuals when in contact with sheep or other ruminant species.
\end{abstract}

\section{Introduction}

Oestrus ovis is an infectious parasite of small ruminants and sheep in particular. Oestrus ovis develops in the nasal cavity and nasal sinuses of sheep and affects the mucus membranes of the conjunctiva of accidental hosts of other mammals including humans. Cases of external ophthalomyisis; where infection is confined to the conjunctiva have been reported in different parts of the world..$^{1-4}$ The infection occurs throughout the year in sheep and lead to economic losses. However, most infections in humans occur in summer or early fall due to the proper environmental conditions that activate the fly. Human infection is often misdiagnosed because of low incidence rate $(0.001 \%))^{2}$ Up to our knowledge, this is the first reportable case of oestrus ovis ophthalmomyiasis in Jordan valley which directly relate the infection with sheep. Similar cases were reported in the temperate Ajloun area of northern Jordan. 5

\section{Case Report}

A 25 years old farmer who is an owner of sheep flock was infected by the larva of oestrus ovis. He felt a foreign body in his right eye when he milked his small-sized flock manually. At first, the patient complained from the sensation of sudden movement of an object in his right eye, which was accompanied with pain and irritation.

Signs appeared shortly after infection which included a rash on both eyelids and then became hyperemic with lachrymal discharge and engorgement of the vessels of the angle of the eye. The patient sought medical advice where two characteristic larvae of oesterus ovis were removed by cotton swab. Amazingly, when the larva was being removed by cotton swab, it would be fleeing from one side of the eye to the other. The patient was then prescribed antibiotic tobramycin.

Despite the medical advice he received, the inflammation was more pronounced on the day after. The eyelids swelled, the conjunctiva was severely congested and the palpebral fissure became narrow owing to cellulitis. The patient went for a second medical advice. A more careful examination of the eye revealed an extra larva on the conjunctiva of the lower eyelid which was removed. The same antibiotic was applied once more alongside antihistamine histal. It took four days for observed improvement of the eye.

\section{Discussion and Conclusions}

Although human external ophthalmomyiasis is rare, it was reported in several countries of middle east, Africa and Europe, $, 6,7$ and other geographical distribution regions, ${ }^{8}$ reported 8 cases in males and 2 in females; the patients age groups was between 25 and 65 years. Amr et al. ${ }^{5}$ reported 17 cases of human external ophthalmomyiasis in male patients and the age groups ranged between 6 and 45 years. Based on these observations; we come to conclude that all age groups are susceptible to infection with more prevalence in males owing to the nature of their work as farmers or workers.

Early detection and removal of the larvae is critical to prevent serious complications including internal ocular myiasis which may lead to blindness as described by Rakusin. ${ }^{9}$ Removal of larvae is a key to healing. The patient starts responding to treatment after complete removal of all infecting larvae.

Physicians in rural remote regions should consider oestrus ovis larval infection in patients with conjunctivitis especially when individuals are in direct contact with sheep. Prompt diagnosis should be based on larval presence, season, and nature of job. Farmers should be educated about the possible health risk and proper control measurements must be applied.
Correspondence: Omran H. Alameri, Department of Basic Medical Sciences, Faculty of Veterinary Medicine, Jordan University of Science and Technology, 22110 Irbid, Jordan.

Tel.: +962.7201000 Ext. 22005 .

E-mail: ohma@just.edu.jo

Key words: oestrus ovis, ophthalmomyiasis, sheep.

Conflict of interests: the author declares no potential conflict of interests.

Received for publication: 9 September 2014. Accepted for publication: 23 September 2014.

This work is licensed under a Creative Commons Attribution NonCommercial 3.0 License (CC BYNC 3.0).

CC Copyright O.H. Alameri, 2014

Licensee PAGEPress srl, Italy

Veterinary Science Development 2014; 4:5628 doi:10.4081/vsd.2014.5628

\section{References}

1. Brown HS Jr, Foos RY. Larval conjunctivitis in California caused by oestrus ovis. Calif Med 1969;111:272-4.

2. Dar MS, Amer MB, Dar FK, Papazotos V. Ophthalmomyiasis caused by the sheep nasal bot, oestrus ovis (oestridae) larvae, in the Benghazi area of eastern Libya. Trans R Soc Trop Med Hyg 1980;74:303-6.

3. Cher I. External ophthalmomyiasis in Australia. Med J Aust 1986;2:335.

4. Reingold WJ, Robin JB, Leipa D, et al. Oestrus ovis ophthalmomyiasis externa. Am J Ophthalmol 1984;97:7-10.

5. Amr ZS, Amr BA, Abo-Shehada MN. Ophthalmomyiasis externa caused by oestrus ovis L. in the Ajloun area of northern Jordan. Ann Trop Med Parasitol 1993;87:259-62.

6. Arslan F, Mete B, Oztürk R, Samasti M. External ophthalmomyiasis caused by oestrus ovis in Istanbul. Trop Doct 2010;40:186-7.

7. Gregory AR, Schatz S, Laubach H. Ophthalmomyiasis caused by the sheep bot fly oestrus ovis in northern Iraq. Optom Vis Sci 2004;81:586-90.

8. GS, AM, SH, et al. External ophthalmomyiasis which was caused by sheep botfly (oestrus ovis) larva: a report of 10 cases. J Clin Diagn Res 2013;7:539-42.

9. Rakusin W. Ocular myiasis interna caused by the sheep nasal bot fly (Oestrus ovis L.). S Afr Med J 1970;44:1155-7. 